\title{
MANAGEMENT OF OCCUPATIONAL STRESS
}

\author{
Lenuţa TRANDAFIR \\ elena.trandafyr@yahoo.com \\ "Al. I. CUZA" POLICE ACADEMY, BUCHAREST, ROMANIA
}

\begin{abstract}
Stress is an important problem in the majority of countries. Apart from the fact that it is responsible for numerous diseases, it also causes much suffering. Stress appears as an adaptation reaction of our body to those external factors that we perceive as being agressive and which frequently lead us to an alarm state, felt both psychically (tension, fear, anxiety), and physically (increase of the adrenaline secretion, intensity of heartbeats, sweating). It isn't actually a disease, but it can lead to sickness in time. This is why it is good to know what stresses us and how we can escape stress.
\end{abstract}

\section{Keywords}

Management, stress, occupational health, individual, organization

\section{Introduction}

Interest towards the individual's state at work and its relationship with the professional performances has generated a series of researches in the field of organizational psychology.

Occupational stress is one of the multiple issues that the modern society fights. It is generated by professional life, work environment, with direct consequences on the professional activity, but also on the health of those performing the respective work.

The last 50 years have changed profoundly the nature of society in general and of the workplaces, in particular. This is a consequence of the explosive changes of technology, aggressive penetration of the computerization processes, but also modernization of managerial systems.
We assist, after the $1980 \mathrm{~s}$, to the start of some managerial processes that include the operation at the level of the great privatization and merger of the industrial giants, at the reengineering processes and the development of a very active market economy.

International management has become one of the trendy interests of the specialists in the organizational cultures. The rough economical competition in which the current social life is involved is considered to be one of the signs or reactions generating what entered the everyday language as "stress" [1] or "professional stress" or "occupational stress".

In Romania, over the last twenty years, significant economic mutations took place. Important steps were made in passing from an outdated economic system to a capitalist 
one. From the traditional accent on a manufacturing and consumerism production, we gradually moved to an economy mostly oriented on services. This is not easily to see, but it is a reality [2]. What is specific in the nowadays Romanian society is a substantial increase of the stress level and an increase as share of reactions to what was called in literature "stressors".

The consequences of work stress on the working staff were studied carefully, obtaining precise information. The symptoms of occupational stress are easily highlighted and observable, being manifested through behaviours such as the employees encountering certain difficulties in adapting to the changes imposed to the occupied position, the dramatic decrease of work productivity, in other words, a double action is manifested: at the level of the individual who perceives the stressful situation and at the level of the organization on which the existence of a stressful environment falls.

Occupational stress may be defined as being:

- Physical and emotional responses, deleterious, which occur when the requirements of the workplace do not correspond to the individual's skills, resources, needs, leading to the damage or even harm of his/ her health state.

- A cognitive, behavioral and physiological reaction to the aggressive and harmful aspects specific to the job, work environment and organizational climate; it is a state chracterised by high levels of distress and frequently by the feeling of helplessness in meeting tasks.

\section{Patterns of Occupational stress}

Among the "stress pioneers", Walter Cannon and Hans Selye are frequently quoted. Canon was a physiologist and he studied human and animal reactions under dangerous situations. He specified that both animals and humans adopt adaptive responses to stressful situations against which they decide to fight or avoid (Canon names this behavior the reaction of fight or flight). He is also the first to use the term of "stress".

Called "the father of stress", the physician and endocrinologist Hans Selye, defines stress as "a nonspecific response of the human body to any strain on it" [3]. He was the first to make the distinction between the beneficial stress (eustress) and harmful stress (distress). The first motivates the individual, by attracting him into a hard work, the second, if persistent in time, may produce negative reactions on health.

Selye observed that the response sequence to almost any distress or trauma is almost identical. He calls it General Adaptation Syndrome (GAS), consisting in three stages:

1. Alarm reaction - the body mobilizes its resources to fight against stress (the heartbeats and stress hormons increase adrenaline, norepinephrine, epinephrine and cortisone).

2. Resistence - the body fights against the original source of stress, the resistence to other stressors being diminished.

3. Fatigue - the general resistence falls down and the adverse consequences appear: burnout, sickness and even death.

\section{A. The Pattern of Work Stress}

The pattern of work stress [4] considers that the objective environment of work influences the perception of the individual on the ambiance, which, in turn, determines the response from the physiological, behavioral and affective point of view. The effects of these responses may be classified as indicators of mental and physical health or of illness. Within this process, an important role is played by the characteristics of the individual and the interpersonal relationships that influence every step of the process, moderating or exagerating.

\section{B. The Pattern of Individual - Environment Adequacy}

The pattern of individual-environment adjustment/adequacy [5] - starts with the premise that the attitudes, behavior and the other effects at the individual's level result 
from the interraction between the individual's characteristics and those of the environment.

The stress amount felt by an employee is influenced by the individual's perception on the environmen's requirements, and by its perception on its own ability to deal with these requests. Using this pattern, French and his partners have found that a reduced suitability between the individual and the environment is frequently associated with increased reactions to stress. The employees whose skills and abilities are more adequate to the work environment report a low stress level and fewer reactions [6].

\section{Beehr and Newma's Conceptual Pattern}

Beehr and Newman's conceptual pattern (1978) proposes to analyze seven dimensions:

1. environment (all the requirements and characteristics of work or life tasks);

2. individual (psychological, physiological, demographic characteristics; personality type; physical features; anxiety etc.);

3. process;

4. consequences on the individual (psychological effects: anxiety, physical fatigue, depressions, hostility, bournout; physical/physiological effects: cardiovascular diseases, hypertension etc.; behavioral effects: absenteeism, drugs/substances abuse, decrease of work performance etc.;

5. consequences on the organization (decrease of the performance, profit, productivity, staff fluctuation etc.);

6. adaptive responses (consist in management strategies - coping - both on individual level - searching for social support, physical exercises, change of workplace etc. and organizational level - reorganizing the activity, work schedule etc.);

7. time (on which all the other dimensions of occupational stress depend).

\section{Management of Non-Traumatic and Traumatic Stress}

The introduction of the concept of stress in the medical field was linked to the lack felt during the last four decades, in medical practice and theory, of the theoretical framework of the relation between health, illness and behavioral pattern. The use of stress concept provided medicine with a basis to link the external events and the behavior patterns with the internal and biochemical conditions associated to etiology, favorable factors, the onset and maintenance of the diseases.

The use of the terms "stress" and "adaptation" reflects, mainly, the fast increase of the popularity of these two variables. Biological resources are used by the body to respond to stress, as the authors of the adaptation definitions currently note [7].

Due to recent researches on the health state of the contemporaneous society with accent on diet, exercises, control over harmful behaviors (smoking, alcohol, stress), the biological resources have become common in the regimes of stress control, but they are rather used as a reflex, more than a deliberate manner.

In accordance with an overwhelming stressful event, which exceeds the adaptation ability, the individual may react with a transitory dissociative state. The acute stress disorder may precede its posttraumatic disorder. "For a group of post-stress subjects, the presence of this reaction predicted in a percentage of $83 \%$, the occrrence of the posttraumatic stress disorder within the interval considered to be standard, of 6 months, in which it appears subconsequent to psycho-trauma" [8].

The diagnostic criteria of the acute stress disorder, upon DSM-IV

A. The individual who was exposed to a traumatic event in which both the conditions mentioned below were present:

- The person had an experience, was marked or confronted with an event/s that implied the death or the serious injury or a threat to its own physical integrity or the integrity of others.

- The response of the person implied intense fear, helplessness or honour.

B. Either during or after experiencing the traumatic event, the person presents three (or more) of the following dissociative symptoms:

- Subjective sensation of numbness, dettachment or the absence of emotional responsibility; 
- Diminuation of the environment acknowledgement (the person feels "dizzy");

- derealisation;

- depersonalization;

- dissociative amnesia (e.g., the inability to remember an important aspect of the traumatic event).

C. The traumatic event is persistently re-experienced in at least one of the following ways: recurrent images, thoughts, dreams, illusions, flashback episodes or the sensation of reliving the respective experience; or suffering when explosed to events which remind of the suffered trauma;

D. The persistent avoidance of stimuli producing the rememberance of the trauma (e.g., thoughts, feelings, conversations, activities, places, people);

E. Symptoms marked by anxiety or increased excitability (e.g., sleep disorder, iritability, concentration difficulties, hypervigilance, exagerated responses to startle, motor restless);

F. The disorder produces a clinically significant suffering or the alteration of the social or occupational functioning, or in other important fields of activity or diminishes the individual's capacity to meet important tasks, such as obtaining the assistance needed or the mobilization of personal resources by telling the story to family members;

G. The disorder persists minimum 2 days and maximum 4 weeks and appears within the 4-week interval from the traumatic event

H.The disorder is not due to direct, physiological effects of a certain substance (e.g., hearing drug, medication) or to a medical general condition which cannot be better explained by a short psychotic disorder and it is not only an exacerbation of a pre-existent disorder of Axe I or Axe II.

If these symptoms are prolonged more than one week, the diagnostic of posttraumatic stress disorder has to be considered. This disorder is not currently considered a normal response to an intense psycho-trauma. On the contrary, it is considered that the stressful trauma is only the trigger that starts an endogenous response, within an increased individual vulnerability.

DSM-IV defines the characteristics of the psycho-trauma as follows:

1. physical vital threatening to corporal integrity, for example:

- The exposure to a military confrontation, violent attack to self (including rape, robbery), domestic violence, car accidents, child sexual/physical abuse, child neglecting, natural disasters, disease with an superacute, catastrophic onset;

- Being witness to a psychotraumatic event;

- The telling of such a psychotrauma supported by an emotional significant person.

2. A defining feature of the trauma event consists in the fact that the response of the individual implies intense fear, the feeling of helplessness or honour. Due to the intensity of the feelings associated to trauma, its perception can be distorted, so that it can be perceived as fragments of senzations, and the appreciation of time can be altered/ slowed down/accelerated. The feelings can be dissociated by events and the order on which they happened and different grades of total or partial amnesia can appear related to the psycho-trauma event.

The impact of the stress over a person can be manifested in a variety of forms. Stress can affect the way in which the individual approaches the disease and responds to the discomfort state. Also, stress makes a person become irritated, isolated, careful, energetic, optimist, depending on stress nature, if it is negative or positive. While stress can have beneficial effects, the distress may lead to behaviors such as: drug abuse and the approach of a manner which can lead to injury. These behaviors, as well as other similar represent negative ways to stress resolution.

\section{Instead of conclusions}

The accelerated process of globalization of the economy worldwide will inevitably lead to the change of the workforce. More 
and more people will have to form and to continuously inform in order to keep up with this situation, the educational system having the role to answer to the pressures of the division and to the changes at the labour market level on an international plan.

Therefore, it appears the necessity of a "reeducation" and "retraining" of the workforce, necessity which becomes an essential feature of the workplace, influencing the diversity and flexibility of the educational services. The development of the staff and its training cannot be perceived outside the organizational framework, and the organization cannot exist outside the economic environment and the relationships in which it had been constituted, supporting all the influences of this environment and adapting to change in order to maintain or increase the profitability.

The professional activity, as an essential way of human existence to which it cannot give up, generates within the contemporaneous society the most stressful situations. The person involved in the work activity is forced to adapt to certain occupationalorganizational situations. When the organization carries out activities in which risk and overload are current, we deal with stressful situations which can lead to professional or occupational stress. "Lately, stress is predominantly a subject of the organizational behavior. Stress represents a set of circumstances to which the individual cannot respond adequately to ambiental stimuli, or cannot respond with an excessive cost for the body (chronical fatigue, tension, anxiety, loss of self-esteem, depressive states, physical damage)" [9].

The professional stress is defined as " $a$ multicasual and multidimensional phenomenon reflected in the psychophysiological responses of the individual in a certain work situation, manifested in the imbalance between the requests imposed by work and the objective capacity or only subjective of the man to deal with. The causes and effects of the stress are varied and the precise identification of the factors is a rather difficult operation" [10].
In the European Union, occupational stress represents the second health problem linked to professional activity, after dorsal conditions, among the most frequently met health issues at the workplace. These affect $28 \%$ of EU employees.

Occupational stress is the cause of over a quarter of the total medical leaves whose duration represents at least two weeks of absence from the workplace. Occupational stress can be caused by psycho-social risks, such as the design of activities, work scheduling, management (special professional requests and reduced control possibilities over its own activities or issues such as violance and harassement at the workplace). Some physical risks, such as noise and the environment temperature can also cause occupational stress.

The European Parliament is completely involved in approaching the issues linked to the psychological assistance of staff. The prevention of occupational stress represents one of the objectives formulated in the Communicate of the European Commission for Employment and Social Issues, on the new strategy in the field of occupational health and safety.

Initially, occupational stress (O.S.) - whose relatively short history from the perspective of the organizational and work psychology was acknowledged (conceptualized) only at the level of top Managers and labelled as "leading stress/managerial stress" or "stress of the staff with executive attributes". Subsequently, researches were extended to a large range of professions, starting from those situated at the bottom of the organizational pyramid. The occupations characterised by high risk and physical or intense psychical requests, the improper fulfillment or the incompetence of the workload and professional responsibilities may lead to serious errors, accidents and the decrease of the performance at organization level.

The actual knowledge about stress neurophysiology has important implications regarding stress management. Firstly, all these data represent evidence of the fact that stress and trauma have a toxic effect for the 
normal development of the brain. There are no other stronger evidences to show the harm of the stress, therefore, it has to be highlighted the critical importance of the prevention, of the early identification and the efficient intervention to reduce the effects. Such psychological interventions can prevent, minimize or even cancel the harmful effects on the brain development.

\section{Aknowledgement}

This work was possible with the financial support of the Sectoral Operational Programme for Human Resources Development 2007-2013, co-financed by the European Social Fund, under the project number POSDRU/159/1.5/S/138822 with the title "Transnational network of integrated management of intelligent doctoral and postdoctoral research in the fields of Military Science, Security and Intelligence, Public order and National Security - Continuous formation programme for elite researchers - «SmartSPODAS»".

\section{References}

1. Stress is an internal response to a stimulus or external situation, named stressor or stress factor. However, a person can be affected by a stressor, while someone else not. More people exposed to stressors, even traumatized, succed to adapt to situation. Other people manifest intense psychological symptoms and usually for a long time.

2. C. Thomas, Horia Dumitru Pitariu, "From Socialism to Service: Developing Human Resource Management for a Market Responsive Economy", Paper presented at the meeting of the From Socialism to Capitalism: The Role of Human Resource Management in Large Systems Change, (Gummersbach: Germany, June 1991).

3. Hans Selye, The Stress of Life, (New York: McGraw-Hill, 1956).

4. J.R.P. French \& R.L. Kahn, "A programmatic approach to studying the industrial environment and mental health", Journal of Social Issues, 18, (1962): 1-47.

5. J.R. Edwards \& C.L. Cooper, "The person-environment fit approach to stress: Recurring problems and some suggested solutions", Journal of Organizational Behavior, 11, (1990): 293-307.

6. J.R. Edwards, "An examination of competing versions of the person-environment fit approach to stress", Academy of Management Journal, 39, (1996): 292-339; J.R.P. French Jr., R.D. Caplan \& R.V. Harrison, The mechanisms of job stress and strain, (London: Wiley, 1982).

7. Florin Tudose, Fundamente în psihologia medical, (Bucharest: Fundaţia România de Mâine Publishing House, 2008), 59.

8. Dan Prelipceanu, Psihiatrie clinică, (Bucharest: Medicală Publishing House, 2013), 521.

9. http://www.cultura.mai.gov.ro/biblioteca $\% 20$ virtuala/editura $\% 20 \mathrm{mai} /$ managementul $\% 20$ stresului $\% 20$ profesional/Management $\% 20$ stress $\% 20$ profesional $\% 20 \mathrm{vol} \% 201 . \mathrm{pdf}$

10. Irina Anca Tănăsescu, Stresul psihic. Tehnici de reglare a conduitei şi de prevenire a tulburărilor de adaptare, (Bucharest: Axioma Print Publishing House, 2003) The Psychobiology of Stress and Healing, www.isma.org.uk.

\section{Bibliography}

Prelipceanu, Dan, Psihiatrie clinic. Bucharest: Medicală Publishing House, 2013.

Tănăsescu, Irina Anca, Stresul psihic. Tehnici de reglare a conduitei şi de prevenire a tulburărilor de adaptare. Bucharest: Axioma Print Publishing House, 2003; The Psychobiology of Stress and Healing. www.isma.org.uk. 
Tudose, Florin. Fundamente în psihologia medical. Bucharest: Fundaţia România de Mâine Publishing House, 2008.

http://www.cultura.mai.gov.ro/biblioteca\%20virtuala/editura\%20mai/managementul $\% 20$ stres ului\%20profesional/Management $\% 20$ stress $\% 20$ profesional $\% 20 \mathrm{vol} \% 201 . p d f$

http://agency.osha.eu.int

http://europe.osha.eu.int/systems/strategies/future/\#270

http://www.apio.ro/meniu/revista-pru/arhiva-revistei-pru.html 